\title{
Facial musculature in the rhesus macaque (Macaca mulatta): evolutionary and functional contexts with comparisons to chimpanzees and humans
}

\author{
Anne M. Burrows, ${ }^{1,2}$ Bridget M. Waller ${ }^{3}$ and Lisa A. Parr ${ }^{4,5}$ \\ ${ }^{1}$ Department of Physical Therapy, Duquesne University, Pittsburgh, PA, USA \\ ${ }^{2}$ Department of Anthropology, University of Pittsburgh, Pittsburgh, PA, USA \\ ${ }^{3}$ Department of Psychology, University of Portsmouth, Portsmouth, UK \\ ${ }^{4}$ Department of Psychiatry, Emory University, Atlanta, GA, USA \\ ${ }^{5}$ Yerkes National Primate Research Center, Atlanta, GA, USA
}

\begin{abstract}
Facial expression is a common mode of visual communication in mammals but especially so in primates. Rhesus macaques (Macaca mulatta) have a well-documented facial expression repertoire that is controlled by the facial/ mimetic musculature as in all mammals. However, little is known about the musculature itself and how it compares with those of other primates. Here we present a detailed description of the facial musculature in rhesus macaques in behavioral, evolutionary and comparative contexts. Formalin-fixed faces from six adult male specimens were dissected using a novel technique. The morphology, attachments, three-dimensional relationships and variability of muscles were noted and compared with chimpanzees (Pan troglodytes) and with humans. The results showed that there was a greater number of facial muscles in rhesus macaques than previously described (24 muscles), including variably present (and previously unmentioned) zygomaticus minor, levator labii superioris alaeque nasi, depressor septi, anterior auricularis, inferior auricularis and depressor supercilii muscles. The facial muscles of the rhesus macaque were very similar to those in chimpanzees and humans but $M$. mulatta did not possess a risorius muscle. These results support previous studies that describe a highly graded and intricate facial expression repertoire in rhesus macaques. Furthermore, these results indicate that phylogenetic position is not the primary factor governing the structure of primate facial musculature and that other factors such as social behavior are probably more important. The results from the present study may provide valuable input to both biomedical studies that use rhesus macaques as a model for human disease and disorder that includes assessment of facial movement and studies into the evolution of primate societies and communication.
\end{abstract}

Key words chimpanzee; evolution; facial expression; facial muscle; macaque; mimetic; primate.

\section{Introduction}

The rhesus macaque (Macaca mulatta) is the most studied non-human primate, being widely used in many biomedical fields and as a model for the evolution of human social behaviors (e.g. Maestripieri, 1999, 2007; Seth, 2000; Amici et al. 2008; Hemelrijk et al. 2008; Kempes et al. 2008; Machado \& Bachevalier, 2008). Consequently, the anatomy, physiology and behavior of rhesus macaques are often foci in our efforts to understand the processual and mechanistic factors involved in the evolution of these behaviors as well

\section{Correspondence}

Anne M. Burrows, Department of Physical Therapy, Duquesne

University, 600 Forbes Avenue, Pittsburgh, PA 15282, USA.

T: (412) 396.5543; F: (412) 396.4399; E: burrows@duq.edu

Accepted for publication 15 May 2009

Article published online 26 June 2009 as the etiopathogenesis and treatment of human disease and abnormal emotional and social behaviors such as Parkinson's disease, autism, AIDS and schizophrenia (e.g. Collier et al. 2007; Bauman et al. 2008; Wu et al. 2008; Abel, 2009; Degenhardt et al. 2009). One of the most fundamental and salient features of normal primate social and emotional behaviors is the use of facial expressions as a means of close-proximity communication among conspecifics (Darwin, 1872; Schmidt \& Cohn, 2001; Burrows, 2008). In addition, the appropriate production and decoding of facial expressions are widespread measures of the efficacy of treatments for various human diseases/disorders (Tir et al. 2007; Clark et al. 2008; Combs et al. 2008). As rhesus macaques are frequently used as both models of human diseases/disorders and of the evolution of human social behavior, a full understanding of the morphology of their facial expression musculature is essential. 
Macaques as a genus [Cercopithecoidea: Cercopithecidae: Papionini; Groves, (2001)] present a range of social styles (e.g. Thierry, 1990, 2000). At one extreme are the 'tolerant' species such as stump-tailed macaques ( $M$. arctoides), Tonkean macaques ( $M$. tonkeana) and lion-tailed macaques (M. silenus). These species are characterized by relatively relaxed and egalitarian dominance styles with tolerance toward subordinates, low levels of aggression, and high levels of reconciliation and affiliation (de Waal \& Luttrell, 1985; Thiery, 1990, 2000; Flack \& de Waal, 2004; Preuschoft, 2004). Social interactions between and among conspecifics tend to be bidirectional. At the other extreme are the 'despotic' species such as crab-eating macaques (M. fascicularis), pig-tailed macaques ( $M$. nemestrina) and rhesus macaques (M. mulatta). These species are characterized by a rigid dominance hierarchy with little tolerance toward subordinates, unidirectional and high levels of severe aggression and low levels of reconciliation in females. Any affiliations tend to be kin-based.

All species are diurnal, consume a wide variety of foods and live in relatively large, multi-male groups of up to 50 individuals with males usually migrating out of their natal group (Fleagle, 1999; Fooden, 2000). During the day, individuals may split off into smaller foraging groups. Some species, such as $M$. nemestrina and $M$. sylvanus, may practice fission-fusion group dynamics (Fukuda, 1989; Menard et al. 1990; Amici et al. 2008), a highly complex social practice of dividing and reforming over long periods of time, also expressed by chimpanzees (e.g. Goodall, 1986; de Waal, 1998), although the fission-fusion style in macaques may be somewhat different from that practiced by chimpanzees.

In both tolerant and despotic species individuals must communicate with one another and this is done mainly via vocalizations and visual displays such as facial expressions. Both the vocal and facial display repertoires of some macaque species are relatively well understood, especially in rhesus macaques ( $M$. mulatta). Facial displays and vocalizations in this species convey information related to the rank of the sender, individual identity, reproductive status and emotional state/intent of the signaler (van Hooff, 1962; Andrew, 1963; Redican, 1975; Preuschoft, 2000; Gerald et al. 2009). As in humans and chimpanzees, rhesus macaques integrate vocalizations and facial displays and may use these modes both individually and simultaneously (Darwin, 1872; Andrew, 1963; Hinde \& Rowell, 1962; Partan \& Marler, 1999, 2005; Gil-da-Costa et al. 2004; Ghazanfar \& Santos, 2004; Ghazanfar et al. 2005; Schroeder et al. 2008; Chandrasekaran \& Ghazanfar, 2009).

Facial displays are part of the visual communication repertoire in many primate taxa (Darwin, 1872; Goodall, 1986; Zeller, 1987; Bearder et al. 1995; Dunbar, 1998; Schmidt \& Cohn, 2001; Parr, 2003; Byrne \& Bates, 2007; Cheney \& Seyfarth, 2007; Burrows, 2008; Moss, 2008). Although it is clear that rhesus macaques use facial expressions as part of their intraspecific visual communication repertoire (Maestripieri, 1999; Partan, 2002; Aureli \& Schino, 2004), data have been equivocal on their expertise relative to chimpanzees and humans in the cognitive perception of facial expressions (Hoffman et al. 2007; Gothard et al. 2004, 2007, 2009; Parr et al. 2008). Regardless, the facial display repertoire of $M$. mulatta is relatively well understood and consists of displays such as the 'silent-bared teeth' display and the 'relaxed open-mouth' display. These displays have been cited as homologues to human laughter and smiling, respectively (van Hooff, 1972; Preuschoft, 1992). Thus, an increased understanding of rhesus macaque facial display behaviors may inform our understanding of the evolution of human communication and social behavior.

Despite the widespread use of $M$. mulatta in both biomedical models and in models of the evolution of human social behaviors, there is a surprising lack of studies detailing the facial musculature in this species. Recent research has mapped $M$. mulatta facial musculature to facial movements in an effort to increase our comparative understanding of communication via facial expressions in humans (Waller et al. 2008b). However, the structure of the facial musculature in $M$. mulatta remains unclear. Without a thorough structural and functional understanding of these muscles in the rhesus macaque their utility as models of the evolution of human communication and social behavior will be limited as will our efforts at understanding human disease/disorders that involve facial expression.

The anatomical studies that do exist (Huber, 1931, 1933) make no mention of sample size and describe the facial musculature solely with respect to a phylogenetic scheme or the 'scala naturae'. Under this scheme the rhesus macaque, due to its position intermediate to the strepsirrhines and hominoids, has less muscle complexity (fewer muscles that are relatively large and undifferentiated with obtuse attachment sites) than hominoids but more complexity than the strepsirrhines. However, recent research has challenged this general notion of primate facial musculature complexity being arranged according to the 'scala naturae' and suggests that a more useful conceptualization may be one that is grounded in factors such as social group size, ecological setting and other social factors (Burrows \& Smith, 2003; Burrows et al. 2006; Dobson, 2009, in press; Burrows, 2008; Rogers et al. 2009).

An accurate rendering of the facial expression musculature across primate taxa would provide essential evidence in the consideration of how facial displays are incorporated into the primate visual communication repertoire. In addition, a more complete picture of the $M$. mulatta facial musculature would further our understanding of the role of facial expression in the evolution of primate communication and primate societies, and the evolution of human speech/language (Parr \& Waller, 2006; Burrows, 2008; Sherwood et al. 2008; Rogers et al. 2009). In an effort to 
ameliorate this general lack of a comparative framework in facial musculature across the primate order, the present study aims to first provide an accurate account of the M. mulatta facial musculature at the gross level using a relatively large sample size. Secondly, the facial muscles from M. mulatta will be compared with those from the distantly related chimpanzee (Pan troglodytes) and humans in order to test competing hypotheses related to the evolution of primate facial musculature. The chimpanzee [Hominoidea: Hominidae: Homininae; Groves (2001)], like the rhesus macaque, lives in large multi-male/multi-female groups that practice fission-fusion dynamics (although the particular style may differ from that practiced by rhesus macaques) where the large group may break out into numerous smaller groups that interact with other groups and then reunite (e.g. Nishida, 1979; Chapman et al. 1993). There is a rigid male-centered dominance hierarchy and there are frequent intergroup territorial disputes (Goodall, 1986; Foster et al. 2009). As part of their intricate social management networks, chimpanzees intensively use both vocal and visual communication modes and these modes are well-documented (e.g. van Hooff, 1972, 1973; Goodall, 1986; de Waal \& Aureli, 1996; Parr et al. 1998). Although it is difficult to definitively categorize human social groups it is clear that humans have a highly complex social system that is characterized by communication via a well-documented facial display repertoire and speech.

\section{Hypotheses}

The present study tests two competing hypotheses. (1) If social factors are primarily responsible for the evolution of primate facial musculature, then the gross facial musculature in $M$. mulatta is predicted to be nearly identical to that seen in both chimpanzees and humans with the same number of muscles and specific, differentiated attachment sites. A recent study reported 23 individual muscles in chimpanzees (Burrows et al. 2006) and humans are generally reported to have the same number (e.g. Standring, 2004). (2) If, however, phylogenetic factors are primarily responsible for the evolution of primate facial musculature [i.e. the 'scala naturae' of Huber (1931)], we instead expect to see fewer individual muscles in rhesus macaques than in the distantly related chimpanzee and human and these muscles will be less differentiated with obtuse attachments.

\section{Materials and methods}

Faces from six adult male rhesus macaques ( $M$. mulatta) were used in the present study. All specimens came from Yerkes National Primate Research Center (YNPRC) (Atlanta, GA, USA). All specimens were obtained following killing that was carried out by the veterinary staff at YNPRC. These procedures were part of an unrelated study that was carried out at YNPRC. Thus, IACUC approval for the present study was not required but IACUC approval was granted by YNPRC for the unrelated previous research study that provided these specimens. After killing, heads of all specimens were disarticulated from the mid-cervical region of the vertebral column and fixed in $10 \%$ buffered formalin.

A midline incision was made using no. 11 and 12 scalpel blades over the dorsal cervical region, the occipital, frontal and nasal regions, and over the upper and lower lips, and continuing over the ventral region of the neck, creating two separate facial 'masks'. The external ear was cut away from the skull with the facial mask. In some specimens the epidermis, dermis, superficial fasciae and superficial facial musculature was taken with the facial mask leaving the deeper facial musculature with the skull and masticatory muscles. In other specimens the epidermis, dermis and superficial fasciae were removed and all facial musculature was left behind with the skull and masticatory muscles. This allowed for a variety of views of the muscles, their attachments and their three-dimensional relationships with one another. This novel approach of creating a facial mask that also includes the facial musculature allows for a potentially more complete preservation relative to the traditional approach of peeling the skin away from the facial muscles on the skull. This also provides a more complete image of muscle attachments by keeping the superficial portions of musculature attached to the skin and the deeper portions attached to the skull (Burrows \& Smith, 2003; Burrows et al. 2006; Burrows, 2008). The buccinator muscle was always left behind with the skull and was not treated in the present study as a muscle of facial expression to be observed. Although this muscle is innervated by the facial nerve its function is more closely related to feeding than to social communication via facial expression (Standring, 2004).

Once the facial masks were removed they and the facial musculature remaining with the skull were allowed to air dry for approximately $30 \mathrm{~min}$ in order to increase the color contrast among dermis, superficial fasciae and musculature. Superficial fasciae were removed from the musculature using a variety of dissection tools so that each individual muscle was identifiable and distinct from surrounding muscles.

Both the facial masks and the heads with muscles in place were examined for the presence of muscles, their attachments to skin, bone, cartilage and one another, their three-dimensional relationships, and for variation among specimens. Muscles were classified with reference to a variety of sources, both from previous work on M. mulatta (Huber, 1931, 1933) and from cercopithecines (Pellatt, 1979a; Swindler \& Wood, 1982). All muscle attachments were recorded, digitally photographed and stored as digital images on a personal computer.

\section{Results}

Figure 1 shows all of the musculature in place on a facial mask. Figures 2-8 show the musculature located in the specimens, region by region. Table 1 describes the muscle attachments and variation among specimens in $M$. mulatta and Table 2 compares the present results with those from chimpanzees (Burrows et al. 2006) and humans (Standring, 2004).

All specimens had relatively little superficial fasciae covering the superficial facial musculature. These rhesus macaque specimens, unlike humans, possessed few adipose deposits in any region of the face, similar to the condition in chimpanzees (P. troglodytes) (Standring, 2004; Burrows 


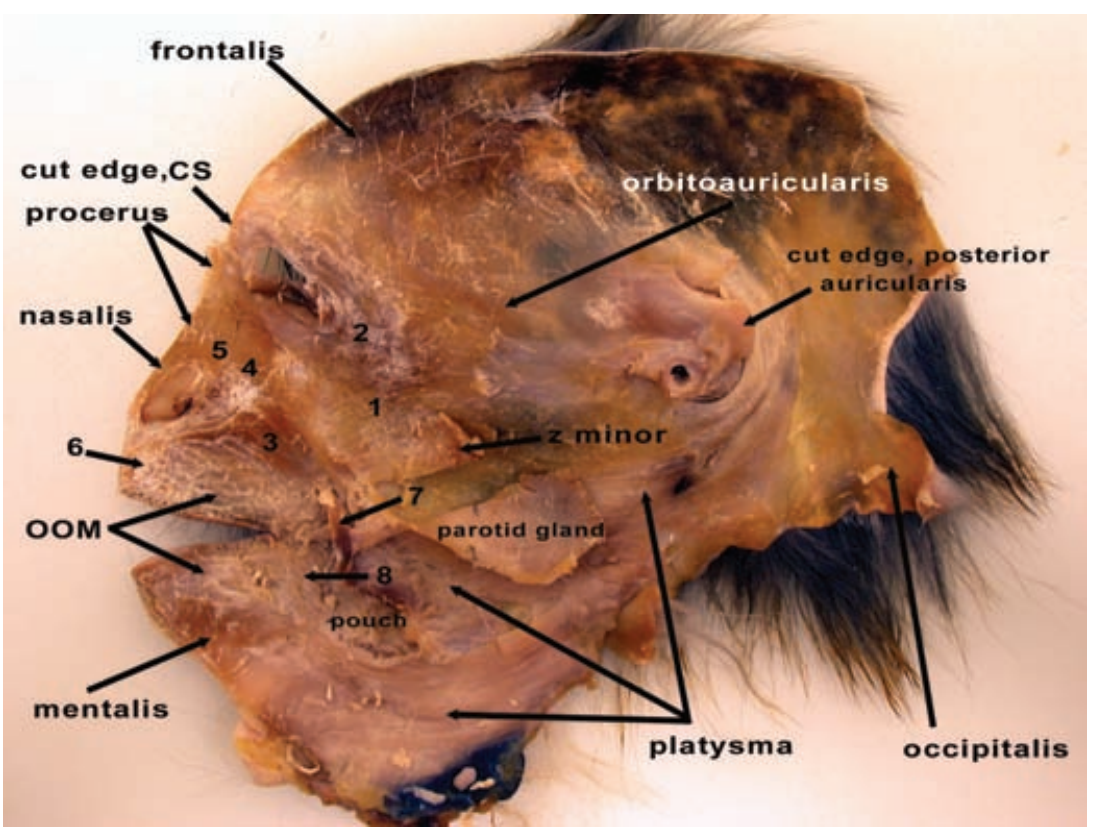

Fig. 1 Deep view of a facial mask from the right side of the head from an adult male $M$. mulatta. 1 , zygomaticus major muscle (m.); 2, orbicularis occuli $m$.; 3 , caninus $m . ; 4$, levator labii superioris $m . ; 5$, levator labii superioris alaeque nasi $m . ; 6$, depressor septi $m . ; 7$, cut edge of buccinator $m$.; 8 , depressor labii inferioris $m$. OOM, orbicularis oris m.; $C S$, corrugator supercilii $\mathrm{m}$.; $z$ minor, zygomaticus minor $\mathrm{m}$.; 'pouch', cheek pouch.

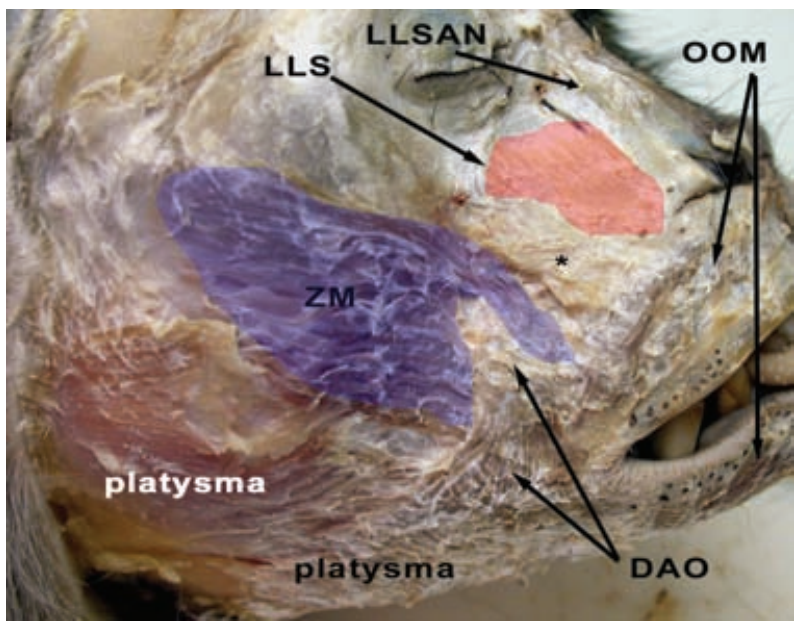

Fig. 2 Right side of M. mulatta head with superficially located facial musculature indicated. ZM, zygomaticus major muscle (m.); LLS, levator labii superioris m.; LLSAN, levator labii superioris alaeque nasi m.; $\mathrm{OOM}$, orbicularis oris $\mathrm{m}$.; DAO, depressor anguli oris $\mathrm{m}$. *Position of the caninus $\mathrm{m}$., which is located deeply. The blue coloration on the ZM and red coloration on the LLS are used to indicate the approximate boundaries of these muscles.

et al. 2006). Over the lateral part of the midface, mental region and superciliary region, the superficial fascia was tightly adherent to the underlying facial musculature, necessitating the use of the scalpel blade to free the musculature from the overlying fascia. In other regions the superficial fascia was only loosely applied to the underlying musculature and was freed using blunt tools.

All muscles (except for those attached to the pinna) were notable in being attached to at least one other facial muscle, a condition that is also seen in humans and

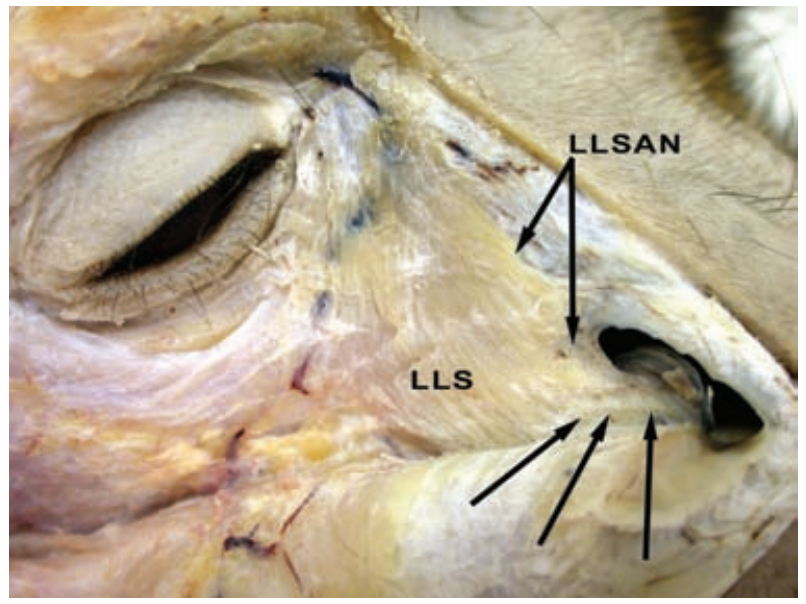

Fig. 3 Right side of M. mulatta head with a close-up of the midfacial region showing the specific attachments of the levator labii superioris alaeque nasi muscle (m.) (LLSAN), indicated by the black arrows. Note that the LLSAN is congruent with the levator labii superioris $m$. (LLS) at its superior attachment but diverges approaching the inferior attachment to the alar region of the nose.

chimpanzees (Standring, 2004; Burrows et al. 2006). Muscles were present in all specimens unless otherwise noted.

\section{Individual muscles (see Tables 1, 2 and Figs 1-8)}

\section{Platysma muscle (Figs 1, 2, 6, 7)}

The platysma muscle in $M$. mulatta is similar to many other primates in being relatively flat, thin and expansive with fibers passing through the dorsal cervical region, inferior to the pinna, splitting around the cheek pouch (see Fig. 1) and attaching into the inferolateral edge of the zygomaticus 


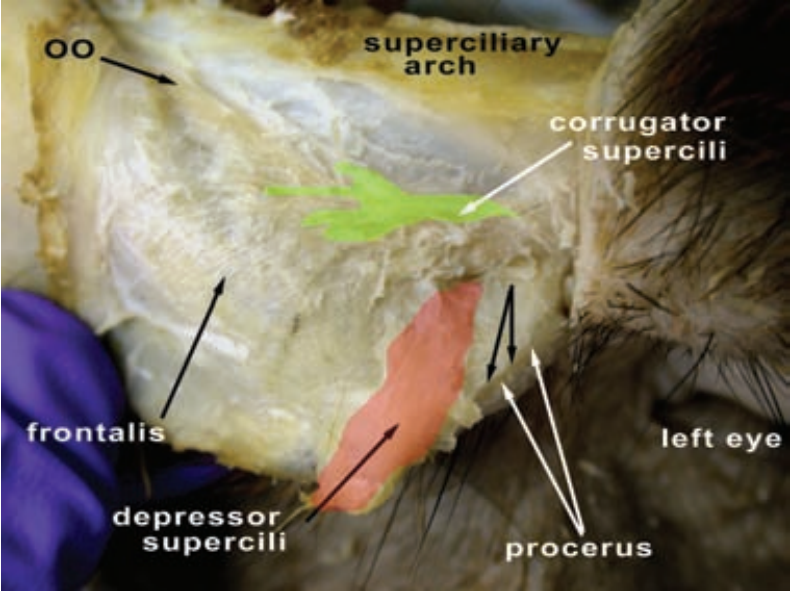

Fig. 4 Right side of $M$. mulatta head with a close-up of the superciliary region. $\mathrm{OO}$, orbicularis occuli muscle $(\mathrm{m}$.). The green coloration on the corrugator supercilii $\mathrm{m}$. and the red coloration on the depressor supercilii $\mathrm{m}$. are used to indicate the approximate boundaries of these muscles. The unlabeled black arrows are used to indicate, with the white arrows labeled 'procerus', the boundaries of the procerus $\mathrm{m}$.

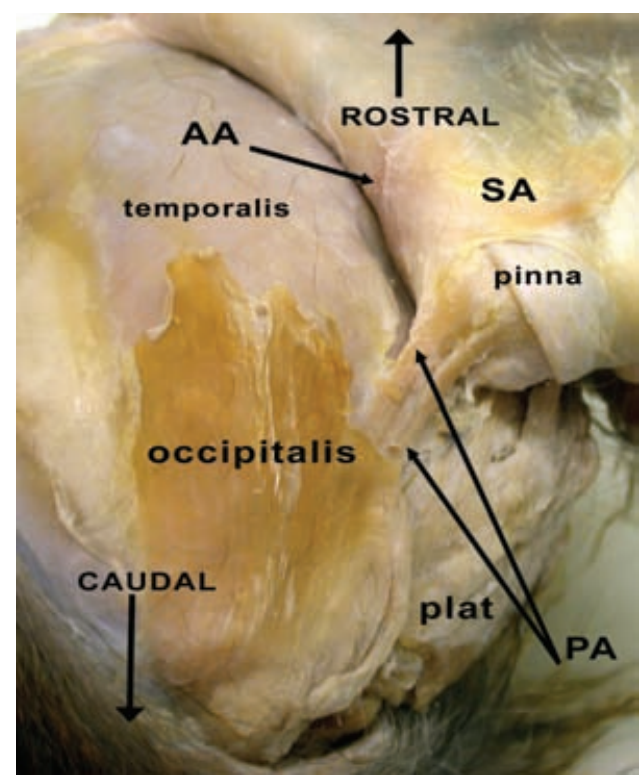

Fig. 5 Right side of M. mulatta head with a posterior view of the skin covering the calvaria and pinna. plat, platysma muscle (m.); PA. posterior auricularis $\mathrm{m}$.; $A \mathrm{~A}$, anterior auricularis $\mathrm{m}$.; $\mathrm{SA}$, superior auricularis $\mathrm{m}$.

major and levator anguli oris muscles. Unlike humans, the rhesus macaque platysma muscle does not directly attach into the modiolar region of the mouth due to the interrupting presence of the depressor anguli oris muscle (see Fig. 7). Inferior fibers of the platysma muscle sweep across the ventral cervical region and interlace with the depressor labii inferioris muscle and the lower fibers of the orbicularis oris muscle. As described in Huber (1933) the platysma muscle is attached caudally to the origin of the

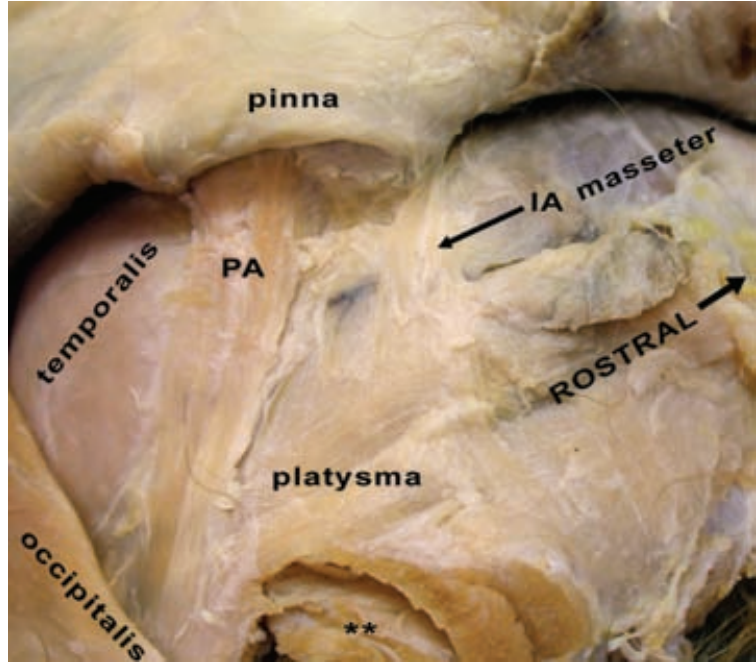

Fig. 6 Right side of M. mulatta head with an inferolateral view of the skin covering the pinna. PA, posterior auricularis muscle (m.); IA, inferior auricularis $\mathrm{m}$. ${ }^{*}$ Musculature of the cervical region.

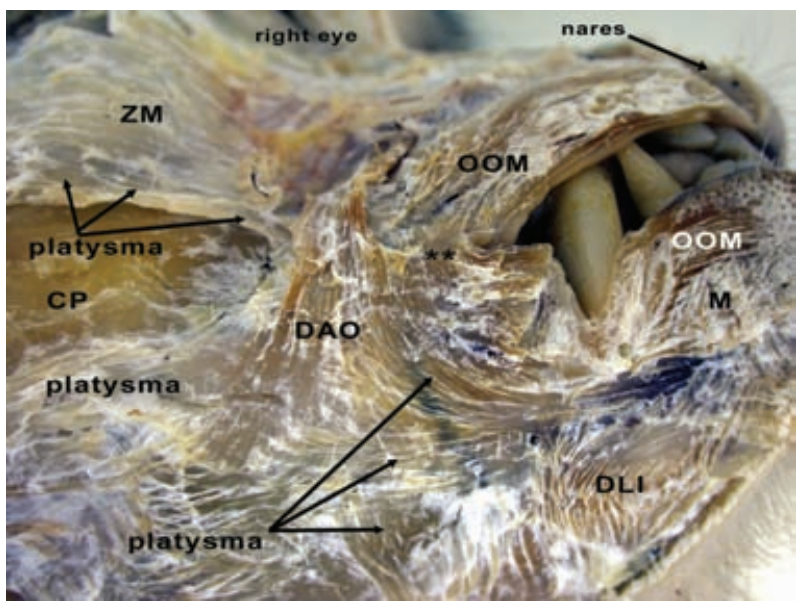

Fig. 7 Right side of M. mulatta with a close-up of the inferolateral aspect of the oral region. ZM, zygomaticus major muscle (m.); OOM, orbicularis oris $\mathrm{m}$.; $\mathrm{DAO}$, depressor anguli oris $\mathrm{m}$.; $\mathrm{DLI}$, depressor labii inferioris $\mathrm{m}$.; $\mathrm{M}$, mentalis $\mathrm{m}$.; $\mathrm{CP}$, region of the cheek pouch. ** Modiolar region.

posterior auricularis and occipitalis muscles, passing deep to the occipitalis muscle (Figs 5,6). As in humans and chimpanzees the platysma muscle in rhesus macaques is easily separable from the overlying fascia.

Although this muscle was not stimulated in a previous study on an anesthetized rhesus macaque (Waller et al. 2008b) its function is probably similar to that in humans based upon its attachments, i.e. tightening the skin of the neck and drawing the lower lip and corner of the mouth inferolaterally (Standring, 2004). Additionally, as the platysma muscle splits around the cheek pouch, it may help to compress the cheek pouch when the individual animal empties it. 
Table 1 Facial musculature in M. mulatta

\begin{tabular}{|c|c|}
\hline Muscle & Attachments \\
\hline Platysma & $\begin{array}{l}\text { Nuchal crest; skin over lateral aspect of face and ventral and lateral aspect of neck; attached anteriorly to caninus } \\
\text { m., lower fibers of orbicularis oris } \mathrm{m} \text {. and depressor anguli oris } \mathrm{m} . ; \text { ventrally to depressor labii inferioris } \mathrm{m} \text {. and } \\
\text { mentalis } \mathrm{m} \text {.; splits around cheek pouch }\end{array}$ \\
\hline Occipitalis & $\begin{array}{l}\text { Single muscle belly arising from nuchal crest inserting into galea aponeurotica; origin is medial to posterior } \\
\text { auricularis } \mathrm{m} \text {. }\end{array}$ \\
\hline Frontalis & $\begin{array}{l}\text { Galea aponeurotica near bregma to fascia of superciliary region, intermingling with fibers of corrugator } \\
\text { supercililii } \mathrm{m} \text {.; continues inferiorly mingling with procerus } \mathrm{m} \text {.; connected by fascia to superior auricularis } \mathrm{m} \text {. }\end{array}$ \\
\hline Posterior auricularis & $\begin{array}{l}\text { Originates lateral to occipitalis } \mathrm{m} \text {. at nuchal crest as one belly; diverges into two slips of relatively equal size that } \\
\text { attach into fascia near posterior region of cartilage of pinna; robust }\end{array}$ \\
\hline Superior auricularis & Flat, wide band attached partially to frontalis $\mathrm{m}$.; attaches into fascia near superior region of pinna \\
\hline Anterior auricularis & $\begin{array}{l}\text { Variable; present in } 2 / 5 \text { specimens; very near orbitoauricularis } \mathrm{m} \text {. and imperfectly separated from frontalis } \mathrm{m} . ; \\
\text { attached to fascia near superolateral border of orbit and to fascia near superoanterior portion of cartilaginous pinna }\end{array}$ \\
\hline Inferior auricularis & $\begin{array}{l}\text { Variable; present in } 2 / 5 \text { specimens; superficial to platysma } \mathrm{m} . ; \\
\text { gap between tragus and antitragus and to fascia near superior edge of platysma; smaller than superior or } \\
\text { posterior auricularis } \mathrm{mm} \text {. }\end{array}$ \\
\hline Tragicus & Small but consistent arcing fibers that run from the anterior edge of the helix of the pinna to the tragus \\
\hline Antitragus & Larger arcing fibers that pass from the posteroinferior edge of the pinna root to the antitragus \\
\hline Orbitoauricularis & $\begin{array}{l}\text { Variable; present in } 3 / 5 \text { specimens; rope-like fibers passing from superolateral orbital region to skin near } \\
\text { superoanterior region of pinna; attached to orbicularis occuli } \mathrm{m} \text {. }\end{array}$ \\
\hline Orbicularis occuli & $\begin{array}{l}\text { Gracile sphincter-fibers encircling orbital opening (orbitalis part) and horizontal fibers over eyelid (palpebralis } \\
\text { part); attached medially to medial palpebral region; attaches to orbitoauricularis } \mathrm{m} \text {. and zygomaticus minor m.; } \\
\text { superficial to corrugator supercillii } \mathrm{m} \text {. }\end{array}$ \\
\hline Corrugator supercillii & $\begin{array}{l}\text { Robust fibers deep to orbicularis occuli m.; attached to medial palpebral region and to dermis of superciliary } \\
\text { region near inferior border of frontalis m.; flat and broad }\end{array}$ \\
\hline Depressor supercillii & $\begin{array}{l}\text { Variable; present in } 3 / 5 \text { specimens; located between corrugator supercillii } \mathrm{m} \text {. and procerus } \mathrm{m} . \text {; deep to procerus } \\
\mathrm{m} . ; \text { fibers start near medial palpebral region; attached cranially to dermis around superciliary region }\end{array}$ \\
\hline Procerus & $\begin{array}{l}\text { Medial to corrugator supercillii } \mathrm{m} \text {. and superficial to depressor supercillii } \mathrm{m} . \text {; appears as mingling with inferior } \\
\text { fibers of frontalis } \mathrm{m} \text {.; attached superiorly to frontalis } \mathrm{m} \text {. and inferiorly to skin over nasal bones; gracile fibers }\end{array}$ \\
\hline Zygomaticus major & $\begin{array}{l}\text { Very wide, flat sheet from fascia over zygomatic arch and arch itself; split into a superficial section that attaches } \\
\text { to the upper fibers of the orbicularis oris } \mathrm{m} \text {. and a deep section that attaches to the region of the modiolous; } \\
\text { interrupted by depressor anguli oris } \mathrm{m} \text {.; lateral to zygomaticus minor } \mathrm{m} \text {. }\end{array}$ \\
\hline Zygomaticus minor & $\begin{array}{l}\text { Variable; present in } 2 / 5 \text { specimens; located between zygomaticus major } \mathrm{m} \text {. and levator labii superioris } \mathrm{mm} . ; \\
\text { attached to skin over inferior rim of orbit and to upper fibers of orbicularis oris } \mathrm{m} \text {. and depressor anguli oris } \mathrm{m} \text {. }\end{array}$ \\
\hline Levator labii & $\begin{array}{l}\text { Broad, flat muscle originating from nasal and maxillary bones, medial palpebral region, and inserting into } \\
\text { superioris skin over these areas and upper fibers of orbicularis oris } \mathrm{m} \text {. }\end{array}$ \\
\hline Levator labii & $\begin{array}{l}\text { Variable; present in } 2 / 5 \text { specimens; located medial to levator labii superioris } \mathrm{m} . ; \text { thin set of fleeting fibers going } \\
\text { superioris inferiorly as far as the lateral border of the nostril alaeque nasi }\end{array}$ \\
\hline Depressor septi & $\begin{array}{l}\text { Variable; present in } 2 / 5 \text { specimens; mid-line muscle attaching to the inferior aspect of the skin over the border } \\
\text { between the external nares and to the upper fibers of orbicularis oris } \mathrm{m} \text {. }\end{array}$ \\
\hline Caninus & $\begin{array}{l}\text { Deep to depressor anguli oris } \mathrm{m} \text {. and inferior edge of both zygomaticus } \mathrm{mm} \text {.; robust fibers from the canine fossa } \\
\text { of the maxilla to the modiolar region }\end{array}$ \\
\hline Orbicularis oris & $\begin{array}{l}\text { Robust, multi-layered set of fibers arranged as a sphincter around opening of oral cavity; upper fibers attached } \\
\text { to zygomaticus minor and levator labii superioris mm., lower fibers attached to platysma m., depressor anguli oris } \\
\text { m., depressor labii inferioris } \mathrm{m} . \text {, and mentalis } \mathrm{m} . ; \\
\text { maxilla and mandible }\end{array}$ \\
\hline Depressor anguli & $\begin{array}{l}\text { Superficially-located flat sheet of fibers originating from superficial fascia over upper fibers of orbicularis oris oris } \\
\mathrm{m} \text {. and inferior edge of both zygomaticus mm.; passes between heads of zygomaticus major } \mathrm{m} \text {. and inserts into } \\
\text { modiolar region, lower fibers of orbicularis oris } \mathrm{m} \text {., and the platysma } \mathrm{m} \text {. }\end{array}$ \\
\hline Depressor labii & Thin set of fibers from lower fibers of orbicularis oris $\mathrm{m}$. to skin over mid-neck region ventrally inferioris \\
\hline Mentalis & Narrow but robust set of fibers attached to lower fibers of orbicularis oris $\mathrm{m}$. and skin over mental region \\
\hline
\end{tabular}

m., muscle; mm., muscles.

\section{Occipitalis muscle (Figs 1, 5, 6)}

This is a superficial, flat muscle that is embedded within the superficial fascia, attaching to the skin over the nuchal region and the skin near the coronal suture where it mixes with the galea aponeurotica. It lies superficial and medial to the posterior auricularis muscle (Figs 5, 6). Huber (1933) describes this muscle as originating from the spinous processes of the cervical vertebrae but this attachment 


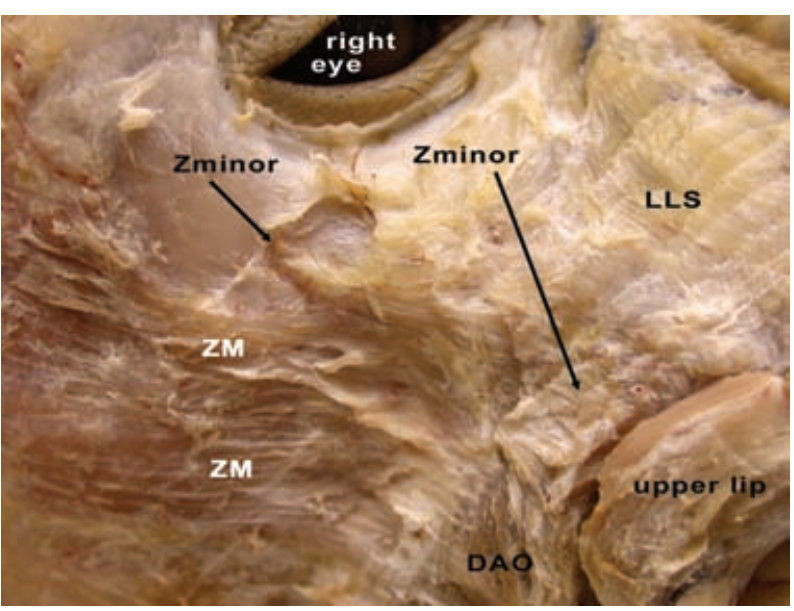

Fig. 8 Right side of $M$. mulatta head with a close-up of the midface showing the appearance and position of the variable zygomaticus minor muscle (m.) (Zminor). ZM, zygomaticus major m.; DAO, depressor anguli oris m.; LLS, levator labii superioris $m$.

Table 2 Comparison of facial muscles between M. mulatta, P. troglodytes and $H$. sapiens

\begin{tabular}{llll}
\hline & M. mulatta & P. troglodytes & H. sapiens \\
Muscle & $\mathrm{P} / \mathrm{A}$ & $\mathrm{P} / \mathrm{A}$ & $\mathrm{P} / \mathrm{A}$ \\
\hline Platysma & $\mathrm{P}$ & $\mathrm{P}$ & $\mathrm{P}$ \\
Occipitalis & $\mathrm{P}$ & $\mathrm{P}$ & $\mathrm{P}$ \\
Frontalis & $\mathrm{P}$ & $\mathrm{P}$ & $\mathrm{P}$ \\
Superior auricularis & $\mathrm{P}$ & $\mathrm{P}$ & $\mathrm{P}$ \\
Posterior auricularis & $\mathrm{P}$ & $\mathrm{P}$ & $\mathrm{P}$ \\
Anterior auricularis & $\mathrm{P} / \mathrm{V}$ & $\mathrm{P}$ & $\mathrm{P}$ \\
Inferior auricularis & $\mathrm{P} / \mathrm{V}$ & $\mathrm{P}$ & $\mathrm{P}$ \\
Orbitoauricularis & $\mathrm{P}$ & $\mathrm{P}$ & $\mathrm{P}$ \\
Tragicus & $\mathrm{P}$ & $\mathrm{P}$ & $\mathrm{P}$ \\
Antitragicus & $\mathrm{P}$ & $\mathrm{P}$ & $\mathrm{P} / \mathrm{V}$ \\
Orbicularis occuli & $\mathrm{P}$ & $\mathrm{P}$ & $\mathrm{P}$ \\
Orbicularis oris & $\mathrm{P}$ & $\mathrm{P}$ & $\mathrm{P}$ \\
Mentalis & $\mathrm{P}$ & $\mathrm{P}$ & $\mathrm{P}$ \\
Levator labii superioris & $\mathrm{P}$ & $\mathrm{P}$ & $\mathrm{P}$ \\
Depressor septi & $\mathrm{P} / \mathrm{V}$ & $\mathrm{P}$ & $\mathrm{P} / \mathrm{V}$ \\
Corrugator supercillii & $\mathrm{P}$ & $\mathrm{P}$ & $\mathrm{P}$ \\
Depressor supercillii & $\mathrm{P} / \mathrm{V}$ & $\mathrm{P}$ & $\mathrm{P}$ \\
Procerus & $\mathrm{P}$ & $\mathrm{P}$ & $\mathrm{P}$ \\
LLSAN & $\mathrm{P} / \mathrm{V}$ & $\mathrm{P}$ & $\mathrm{P}$ \\
Caninus & $\mathrm{P}$ & $\mathrm{P}$ & $\mathrm{P}$ \\
Depressor anguli oris & $\mathrm{P}$ & $\mathrm{P} / \mathrm{V}$ & $\mathrm{P}$ \\
Zygomaticus major & $\mathrm{P}$ & $\mathrm{P}$ & $\mathrm{P}$ \\
Zygomaticus minor & $\mathrm{P} / \mathrm{V}$ & $\mathrm{P}$ & $\mathrm{P} / \mathrm{V}$ \\
Risorius & $\mathrm{P}$ & $\mathrm{P}$ & $\mathrm{P}$ \\
Depressor labii inferioris & $\mathrm{P}$ & $\mathrm{P}$ & $\mathrm{P}$ \\
\hline P & & \\
\hline
\end{tabular}

$P$, present; A, absent; LLSAN, levator labii superioris alaeque nasi m.; V, muscle was variably present (see Table 1). Data for P. troglodytes from Sonntag (1923), Pellatt (1979b) and Burrows et al. (2006); data for humans from Standring (2004). was not noted in the present study. Huber (1933) also notes that the occipitalis muscle in $M$. mulatta attaches to the pinna, creating an 'occipito-auricularis muscle' that is seen in some strepsirrhines (Murie \& Mivart, 1872; Burrows \& Smith, 2003). Such an attachment was not noted in any specimens in the present study. Here, the occipitalis muscle remains distinct from the pinna. Huber (1933) describes a deep head to the occipitalis muscle but this arrangement was not noted in the present study. A robust deep head of the occipitalis muscle is routinely noted in chimpanzees (e.g. Sonntag, 1923; Pellatt, 1979b; Burrows et al. 2006) but is absent in humans.

This muscle was not stimulated by Waller et al. (2008b) but its action probably corresponds to that in humans, based upon its attachments, i.e. drawing the posterior part of the scalp superiorly.

\section{Frontalis muscle (Figs 1, 4, 5)}

The frontalis muscle in $M$. mulatta is a flat, thin, expansive muscle sheet that passes from the galea aponeurotica to the superciliary region where it interlaces with fibers from the corrugator supercilii and orbicularis occuli muscles. At its termination near the superciliary region it passes deep to the orbicularis occuli muscle (Fig. 4). This description is similar to those for humans and chimpanzees. This muscle was stimulated by Waller et al. (2008b) and elevates the skin of the eyebrow region, similar to actions found in humans and chimpanzees that were stimulated (Waller et al. 2006).

Posterior auricularis muscle (Figs 1, 5, 6)

The posterior auricularis muscle is a large, independent, two-headed muscle that arises as a single muscle belly from the nuchal region deep to the occipitalis muscle and medial to the platysma muscle. Anteriorly, it attaches as two separate muscle slips to the antihelix of the pinna, posterior to the attachment of the superior auricularis muscle. This morphology is different from that seen in the chimpanzee and humans where the posterior auricularis muscle is a single muscle belly when present. This muscle was not stimulated by Waller et al. (2008b) but its action probably corresponds to that in humans, based upon its attachments, i.e. drawing the external ear caudally.

\section{Superior auricularis muscle (Fig. 5)}

The superior auricularis muscle is wide, flat and thin, very unlike the posterior auricularis muscle. This muscle is attached medially to the galea aponeurotica and partially to the superolateral edge of the frontalis muscle, passing laterally to the fascia near the helix of the pinna. Huber (1933) described a unified 'auricularis anterior et superior' but the present study found that these muscles are separate when the anterior auricularis muscle is present at all (see below). The superior auricularis muscle is present in humans and chimpanzees. This muscle was stimulated by 
Waller et al. (2008b) and caused the external ear to be elevated superiorly.

\section{Anterior auricularis muscle (Fig. 5)}

This muscle was present in only two of the six specimens $(33.33 \%)$. When present it was imperfectly separated from the anterolateral edge of the frontalis muscle. It was attached to the fascia near the superolateral border of the orbit, near the orbitoauricularis muscle, and to the fascia near the superoanterior portion of the helix. Huber (1933) treats it as a single muscle fused with the superior auricularis muscle (see above). Although variable in M. mulatta this muscle is always present in humans and chimpanzees. This muscle was not stimulated by Waller et al. (2008b) but its function probably corresponds to that seen in humans based upon its attachments, i.e. drawing the external ear superiorly and rostrally.

\section{Inferior auricularis muscle (Fig. 6)}

The inferior auricularis muscle was present in two of the six specimens (33.33\%). When present it was a set of narrow, longitudinally oriented fibers that originated near the superior edge of the platysma muscle (but clearly distinct from it) and inserted into the region of the antitragus. This muscle was clearly separate from the intrinsic muscles of the pinna (the tragicus and antitragicus muscles). This muscle is not reported for humans or chimpanzees and bears no resemblance to nearby muscles reported for any of these species. The mandibuloauricularis and atollens aurem muscles of strepsirrhines are in the general vicinity of the presently reported muscle but are more deeply located and have different attachments (Murie \& Mivart, 1872; Lightoller, 1934; Burrows \& Smith, 2003). This muscle was stimulated by Waller et al. (2008b) and caused the external ear to flatten against the head.

\section{Tragicus muscle}

This small intrinsic muscle of the pinna presents as a set of arching fibers that are attached to the anterior edge of the helix and to the tragus, consistent with the description from Huber (1933). This muscle is documented in humans and chimpanzees. Stimulation of this muscle was not attempted by Waller et al. (2008b) due to its small size. Function of the human tragicus muscle is largely unknown but this muscle may generally serve to produce fine movements of the external ear in humans and rhesus macaques.

\section{Antitragus muscle}

The antitragus muscle in $M$. mulatta was regularly present as arcing fibers from the root of the pinna to the antitragus, very similar to the description of Huber (1933). This muscle was not noted in chimpanzees but has been reported in humans. Stimulation of this muscle was not attempted by Waller et al. (2008b) due to its small size. Function of the human tragicus muscle is largely unknown but this muscle may generally serve to produce fine movements of the external ear in humans and rhesus macaques.

Orbitoauricularis muscle (Fig. 1)

This muscle is variable, being present in three of the six specimens $(50 \%)$. When present it was a robust set of rope-like fibers passing from the superolateral border of the orbit to the skin near the superoanterior region of the pinna, very near the superior auricularis muscle and, when present, the anterior auricularis muscle. It is reported in the greater bushbaby (Burrows \& Smith, 2003) and Huber (1933) reports it for M. mulatta. However, Huber (1933) describes it as a muscle 'plate', being undifferentiated from the other muscles of the frontal and auricular regions, unlike its defined and differentiated condition in the present study. It has not been reported in chimpanzees or humans. This muscle was stimulated by Waller et al. (2008b) and caused the external ear to be elevated superomedially.

\section{Orbicularis occuli muscle (Figs 1, 4)}

This muscle appears similar to the orbicularis occuli muscle across the primate order (e.g. Lightoller, 1928; Swindler \& Wood, 1982; Burrows \& Smith, 2003; Standring, 2004; Burrows et al. 2006). It is a relatively thin, sphincter-like set of fibers that encircles the opening of the orbit, constituting the pars orbitalis, and a set of thin horizontal fibers over the eyelid, constituting the pars palpebralis. Medially, the pars orbitalis is attached to the medial palpebral region. The sphincter fibers also attach to the orbitoauricularis muscle (when present), frontalis muscle and corrugator supercilii muscle. Although the depressor supercilii and procerus muscles lay near the orbicularis occuli muscle, they did not attach to it. The orbicularis occuli muscle lies superficial to the levator labii superioris muscle and superomedial to the zygomaticus major and minor muscles.

Huber (1933) describes the orbicularis occuli muscle of M. mulatta as being fused to the zygomaticus major muscle, forming a zygomatico-orbitalis muscle. The present study consistently found these two muscles to remain distinct and separate. This muscle was stimulated by Waller et al. (2008b) and caused constriction of the eye opening.

\section{Corrugator supercilii muscle (Figs 1, 4)}

This muscle is consistently present as a set of robust, fan-like fibers deep to the orbicularis occuli muscle. Inferiorly it is attached to the medial palpebral region with the orbicularis occuli muscle pars orbitalis and superiorly it is attached to the skin of the superciliary region near the inferior border of the frontalis muscle. It lies deep and lateral to the depressor supercilii and procerus muscles. This muscle is reported in humans and chimpanzees. Although Huber (1933) describes the connections among the corrugator 
supercilii, frontalis and orbicularis occuli muscles as being in a 'primitive' state relative to higher catarrhines, these same arrangements are noted in humans and chimpanzees. Thus, it would be an error to describe this condition as 'primitive' in M. mulatta relative to chimpanzees and humans. This muscle was stimulated by Waller et al. (2008b) and caused the skin of the eyebrow to move inferomedially.

\section{Depressor supercilii muscle (Fig. 4)}

The depressor supercilii muscle is variable, being present in three of the six specimens (50\%). When present it is superficial to the corrugator supercilii muscle and deep and lateral to the procerus muscle. The fibers originate inferiorly with the corrugator supercilii muscle at the medial palpebral region and ascend to attach into the skin of the superciliary region. It is similarly described in humans and chimpanzees. Huber (1933) describes this muscle in rhesus macaques similar to its attributes in the present study. This muscle was unable to be stimulated by Waller et al. (2008b) in an anesthetized rhesus macaque, possibly due to its variable presence.

\section{Procerus muscle (Figs 1, 4)}

This small, thin muscle is located medial to the corrugator supercilii muscle and superficial to the depressor supercilii muscle. It is separated from the frontalis muscle by a thin break in fibers but maintains fascial connections with the frontalis muscle. Superiorly it is attached to the skin over the glabellar region and inferiorly to the skin over the nasal bone. The procerus muscle is described in humans and chimpanzees. Huber (1933) describes this muscle similar to the present study. This muscle was stimulated by Waller et al. (2008b) and caused the medial portion of the skin of the eyebrow to be depressed inferiorly.

\section{Zygomaticus major muscle (Figs 1, 2, 7)}

The zygomaticus major muscle found in the present study is distinguished from the descriptions of Huber (1933) who described the 'zygomatic-orbitalis muscle' and simultaneously the 'zygomaticus muscle mass'. Here, the zygomaticus major muscle is a broad and flat sheet lateral to the zygomaticus minor muscle (when present) and the levator labii superioris muscle. It is clearly distinguished from the orbicularis occuli muscle, which lies partially superficial to it. The zygomaticus major muscle is attached superolaterally to the zygomatic arch and the skin over this region. As it progresses inferomedially it splits into a medially located superficial head that attaches to the upper fibers of the orbicularis oris muscle and a laterally located deep head that passes deep to the depressor anguli oris muscle, inserting into the modiolar region. This same division into deep and superficial heads was described in chimpanzees (Burrows et al. 2006). The zygomaticus major muscle in humans is typically described as a single muscle mass but a common variant is a bifid condition (e.g. Pessa et al. 1998). This muscle was stimulated by Waller et al. (2008b) and caused the corner of the mouth to be elevated and drawn laterally.

\section{Zygomaticus minor muscle (Figs 1, 8)}

The zygomaticus minor muscle is described here for the first time in the rhesus macaque. It is variably present (two of six specimens, 33.33\%) and is located between the zygomaticus major and levator labii superioris muscles. It is attached superiorly to the skin over the inferior rim of the orbit, superficial to the orbicularis occuli muscle, and inferiorly to the upper fibers of the orbicularis oris muscle. When present, the zygomaticus minor muscle is separable from the zygomaticus major muscle superolaterally. This muscle is described in humans and chimpanzees. This muscle was unable to be stimulated by Waller et al. (2008b), possibly due to its variable presence.

\section{Levator labii superioris muscle (Figs 1-3, 8)}

The levator labii superioris muscle is a broad flat sheet that attaches superiorly to the nasal and maxilla bones, medial palpebral region and skin superficial to these regions. Inferiorly it attaches into the upper fibers of the orbicularis oris muscle medial to the zygomaticus muscles. It is regularly described in humans and chimpanzees. Huber (1933) describes this muscle in rhesus macaques as lying deep to a muscle sheet called the 'nasolabialis muscle'. The present study did not locate the nasolabialis muscle. The levator labii superioris muscle was stimulated by Waller et al. (2008b) and caused elevation of the upper lip.

\section{Levator labii superioris alaeque nasi muscle (Figs 1-3)}

This muscle is variably present (two of the six specimens, $33.33 \%$ ) and was located medial to the levator labii superioris muscle. It presents as a long, narrow set of fibers attaching superiorly to the nasal bone and the medialmost edge of the maxilla with the levator labii superioris muscle. As the levator labii superioris alaeque nasi muscle (LLSAN) descends toward the nares, it diverges from the levator labii superioris muscle and attaches inferiorly to the lateral border of the alar region of the nostril. This muscle is described in humans and chimpanzees. Huber (1933) does not describe this muscle. This muscle was stimulated by Waller et al. (2008b) and wrinkled the skin along the lateral portion of the nasal region.

\section{Depressor septi muscle (Fig. 1)}

This muscle was present in two of the six specimens (33.33\%) and ran from the inferior edge of the border between the external nares to the upper fibers of the orbicularis oris muscle. It is described in humans and chimpanzees. Huber (1933) does not describe the depressor septi muscle in his study on the rhesus macaque. Stimulation of this muscle was not attempted by Waller et al. (2008b). On the basis 
of its attachments it may function similarly to humans, i.e. drawing the nasal septum inferiorly.

Caninus muscle (Fig. 1)

The caninus muscle, known in humans as the levator anguli oris muscle (Standring, 2004), is deep to the depressor anguli oris muscle and the inferior edges of both zygomaticus muscles. It is a robust set of fibers attaching medially to the canine fossa of the maxilla and inferolaterally into the modiolar region. It is described in humans and chimpanzees. Huber (1933) describes the caninus muscle similarly to the present study but states that it is part of the orbicularis oris muscle. The present study finds no justification for this description, noting a complete fascial cleft between these muscles. This muscle was unable to be stimulated by Waller et al. (2008b) but its function, based upon its attachments, is probably similar to that in humans, i.e. elevating the corner of the mouth.

\section{Depressor anguli oris muscle (Figs 1, 2, 7, 8)}

This superficial muscle is a flat triangular-shaped sheet of fibers that attaches to the superficial fascia over the upper fibers of the orbicularis oris muscle and both zygomaticus muscles. Inferiorly, it passes between the two heads of the zygomaticus major muscle and attaches into the modiolar region and the lower fibers of the orbicularis oris muscle. The caninus muscle lies partially deep to this muscle. Huber (1933) describes this as the triangularis muscle, similar to the present description. However, it is referred to as the depressor anguli oris muscle in chimpanzees (Burrows et al. 2006), humans (Standring, 2004) and M. mulatta in Waller et al. (2008b). Stimulation of this muscle by Waller et al. (2008b) caused the corners of the lips to be depressed in an inferior direction.

Orbicularis oris muscle (Figs 1, 2, 7)

The orbicularis oris muscle in rhesus macaques is very similar to that reported across the primate order (e.g. Lightoller, 1928; Swindler \& Wood, 1982; Burrows \& Smith, 2003; Standring, 2004; Burrows et al. 2006). It is a robust, multi-layered muscle arranged as a sphincter around the opening of the oral cavity. The upper fibers are attached to the caninus, zygomaticus major and minor muscles, depressor septi muscle, and levator labii superioris muscle. The lower fibers are attached into the platysma, depressor labii inferioris and mentalis muscles. Both upper and lower fibers are also attached into the alveolar margins of the maxilla and mandible. Stimulation of this muscle by Waller et al. (2008b) caused the opening of the oral cavity to be constricted and caused pursing of the lips.

\section{Depressor labii inferioris muscle (Fig. 7)}

This muscle lies inferomedial to the depressor anguli oris muscle and is attached to the skin over the ventral neck (rostral to the platysma muscle) and into the lower fibers of the orbicularis oris muscle. It is described in humans and chimpanzees. Huber (1933) does not describe this muscle but instead shows the ventral portion of the platysma muscle extending to the region where the present study describes the depressor labii inferioris muscle. The present study finds a clear break between the platysma muscle and the lower fibers of the orbicularis oris muscle. Stimulation of this muscle by Waller et al. (2008b) caused the medial portion of the lower lip to be depressed inferiorly.

\section{Mentalis muscle (Figs 1, 7)}

The mentalis muscle in rhesus macaques is similar to descriptions across the primate order (e.g. Lightoller, 1928; Swindler \& Wood, 1982; Burrows \& Smith, 2003; Standring, 2004; Burrows et al. 2006). It is a narrow set of fibers attached to the skin over the mental region and to the lower fibers of the orbicularis oris muscle. Stimulation of this muscle by Waller et al. (2008b) pushed the skin over the mental region superiorly.

\section{Discussion}

The present study relates the first systematic description of the facial musculature in the rhesus macaque ( $M$. mulatta) using a relatively large sample size. Five previously undocumented muscles were described here (see Huber, 1931, 1933): the inferior auricularis, LLSAN, zygomaticus minor, depressor septi and depressor labii inferioris muscles. This study also tested two hypotheses. The first was that social factors are primarily responsible for the evolution of primate facial musculature and this should be reflected in M. mulatta having nearly identical facial musculature relative to chimpanzees and humans, with the same number of muscles and specific, differentiated attachment sites. The alternative hypothesis was that phylogenetic factors are primarily responsible for the evolution of primate facial musculature and this should be reflected in M. mulatta having fewer individual muscles than chimpanzees and humans and these muscles being less differentiated with obtuse attachments. Clearly, the results of the present study are more supportive of the first hypothesis than the second. The rhesus macaques used in the present study had 24 small, well-differentiated individual muscles with discrete attachment sites, very similar to those seen in chimpanzees (23 muscles) and humans (23 muscles). Obviously, the facial muscles in $M$. mulatta are more complex than previously reported (e.g. Huber, 1931). Although $M$. mulatta is relatively distantly related to P. troglodytes and Homo sapiens, morphology of the facial musculature is very similar among these three species, showing adaptive convergence in structure.

Part of the explanation for these results may lie in the methodology used in the present study compared with previous methodologies. In the present study the face was removed from the skull in half of the specimens, taking 
the superficially located musculature with the facial 'mask' and leaving the more deeply located facial musculature behind with the skull. Other studies separate the skin from all underlying musculature. Additionally, the facial mask and the muscles left with the skull were all allowed to air dry, a technique that has not been described for any previous study. These techniques increase the visibility of the musculature and may preserve a greater number of small muscles that were previously missed.

In the midfacial region the previously undescribed zygomaticus minor, LLSAN and depressor septi muscles were noted. Studies on the closely related cercopithecines Cercopithecus aethiops (vervet monkey) and Papio ursinus (chacma baboon) reference none of these muscles (Pellatt 1979a,b; Swindler \& Wood, 1982). The zygomaticus minor muscle found in the present study may represent the 'malaris muscle' described by Pellatt $(1979 a, b)$ for C. aethiops and Papio ursinus. The malaris muscle was drawn as lying medial to the zygomaticus muscle, blending with it inferiorly, and attaching superiorly to the lateral region of the superciliary arch. Both the LLSAN and depressor septi muscles have been found in the chimpanzee (Burrows et al. 2006) and humans. The present study provides evidence for their presence in rhesus macaques. Although the present study did not locate the nasolabialis muscle described by Huber (1933) it is likely that these superficially located muscle fibers are instead the attachments of the levator labii superioris and LLSAN muscles into the overlying skin and not in fact a separate muscle.

The zygomaticus mass or orbito-zygomaticus muscle described by Huber $(1931,1933)$ was clearly shown here to be a distinct muscle separate from the orbicularis occuli muscle with its own distinct attachments, which we label the zyogmaticus major muscle. This muscle appears here to be the same as in chimpanzees with a superficial head and a deep head (Burrows et al. 2006), not in a more primitive state. What is missing in the rhesus macaque midface that is present in chimpanzees (and in humans) is a risorius muscle. No trace of a risorius muscle was found in any specimen in the present study. However, this muscle appears to be highly variable in chimpanzees and humans (Sonntag, 1923; Standring, 2004; Burrows et al. 2006). Its absence from rhesus macaques in the present study may mean that it is truly absent in this species or, as in humans and chimpanzees, its presence is variable.

In the superciliary region of $M$. mulatta the same arrangement is found as in P. troglodytes. Although Huber (1933) describes the orbicularis occuli, corrugator supercilii, depressor supercilii and procerus muscles as being firmly attached to one another the present study finds these muscle to be distinct as in $P$. troglodytes and humans. Pellatt $(1979 a, b)$ describes the depressor supercilii muscle as being variably present in Papio ursinus but states that the procerus muscle is never present. The variable presence of the depressor supercilii in M. mulatta is especially inter- esting given the inability to locate facial movement in an anesthetized rhesus macaque following attempted electrical stimulation of this muscle (Waller et al. 2008b). Interestingly, despite widespread acknowledgement of the variation in facial musculature within primate species (e.g. Standring, 2004; Burrows et al. 2006; Burrows \& Cohn, in press), the extent and patterns of variation have rarely been examined. Recent studies in human facial muscles have identified patterns to variation, in that certain muscles are invariant whereas others are highly variable (Waller et al. 2008a). The invariant muscles seem to be related to universal, basic emotions, whereas the variable muscles may be related to more culturally or individually specific facial emotions (Ekman, 1999; Waller et al. 2008a). Thus, similar approaches may be useful when examining the variation that we see both within and between primate species.

The present study also demonstrated notable findings for muscles of the external ear in M. mulatta. The superior auricularis and anterior auricularis muscles were found to be separate and distinct (when the anterior auricularis muscle was present), contrary to previous descriptions in rhesus macaques and cercopithecines being one continuous sheet of musculature, the auricularis superior et anterior muscle (Huber, 1933; Pellatt, 1979a,b). These two muscles have also been described as being separate entities in chimpanzees and humans. The presence of an inferior auricularis muscle (albeit variable) was somewhat surprising as it has not been reported in hominoids or cercopithecines. However, Waller et al. (2008b) provoked movement of the external ear concordant with the attachments of the presently described muscle. The muscle in the present study appeared as a well-defined, delineated, longitudinally-oriented bundle of muscle fibers passing into the inferior portion of the pinna. As rhesus macaques are noted in moving the external ear frequently in their facial communication repertoire (Partan, 2002; Waller et al. 2008b) it is not surprising to document more muscles associated with movement of the pinna than in other species.

Both humans and chimpanzees have the greatest number of individual facial muscles in the area of the oral cavity/lips and M. mulatta is similar (Standring, 2004; Burrows et al. 2006; Burrows, 2008). Like chimpanzees and humans, rhesus macaques live in relatively large multi-male/multi-female social groups with complex social dynamics including defined dominance hierarchies (e.g. Nishida, 1979; Goodall, 1986). Rhesus macaques and other macaque species regulate intragroup conflict and perform post-conflict reconciliation that involves frequent use of vocal and visual communication (de Waal \& Yoshihara, 1983; Das et al. 1998; Flack \& de Waal, 2004). Both of these communication modes require the use of facial musculature concentrated around the oral cavity/lips to alter the shape of the lips for vocalizations seen in such displays 
as the silent-bared teeth display and relaxed open-mouth displays (Darwin, 1872; de Waal \& Luttrell, 1985; Preuschoft, 1992). These behavioral observations from rhesus macaques may indeed reflect the preponderance of musculature clustered around the lips.

\section{Comparative contexts}

Findings from the present study provide insight into both the use of facial expressions in rhesus macaques and the evolution of primate facial musculature and facial expression. Our current understanding of primate facial musculature, its evolution and the use of facial expression as a mode of communication is almost entirely rooted in a purely 'scala naturae' scheme (Ruge, 1885; Lightoller, 1928, 1934; Huber, 1931, 1933). In this setting the complexity of both the facial musculature and facial expression repertoire of a species are dictated by that species' position on the phylogenetic scale with the most primitive primates, the lorisoids (Strepsirrhini: Lorisiformes), having only a few, sheet-like, undifferentiated muscles with a correspondingly limited expression repertoire. As one ascends the phylogenetic scale each node gains complexity in musculature and function until humans, where the highest structural and functional complexity is said to lie.

Recent work has disputed this notion by finding much greater structural and functional complexity in primate taxa than reported in previous studies (Sonntag, 1923; Pellatt, 1979b; Burrows \& Smith, 2003; Burrows et al. 2006; Burrows, 2008; Diogo, 2009). The present study also reports more structural complexity in rhesus macaques than in a previous study (Huber, 1933), finding that they are not more primitive in muscle complexity than chimpanzees or humans. Instead, they have a large number (24) of individual muscles with discrete attachment sites and they possess most of the same musculature as chimpanzees and humans. Rhesus macaques from the present study were noted to be missing the risorius muscle and the deep head to the occipitalis muscle. Although this may indicate a reduced ability to draw the corner of the mouth posteriorly, the lack of a deep head to the occipitalis muscle may have no communicative correlate. However, both humans and chimpanzees vary considerably in the presence of a risorius muscle among individuals. Interestingly, rhesus macaques from the present study had very large levator anguli oris muscles, which are reported to be either missing from chimpanzees or present as small slips of musculature (Sonntag, 1923; Pellatt, 1979b; Burrows et al. 2006). Recent behavioral work on rhesus macaques and closely related Macaca species indicates that elevation of the corners of the mouth in this species is a frequent component of their facial expression repertoire (Preuschoft, 1992; Das et al. 1998).

Overall, the present study finds little evidence to indicate decreased structural complexity in the facial musculature of the rhesus macaque relative to chimpanzees and humans. Given the results of the present study in combination with recent comparative evidence from the musculature in strepsirrhines, chimpanzees and other primates (Burrows \& Smith, 2003; Burrows et al. 2006; Burrows, 2008; Diogo, 2008, 2009), comparative neurobiological data (Sherwood et al. 2003, 2005; Sherwood, 2005) and data on facial mobility in various primate taxa (Dobson, 2009) the traditional 'scala naturae' model of conceptualizing primate facial musculature seems to be highly suspect in understanding primate facial expression, its evolution and the evolution of primate societies and communication.

\section{Conclusions}

Overall it is clear that the facial muscles of the rhesus macaque ( $M$. mulatta) are more complex than previously described and are structurally similar to those in the chimpanzee ( $P$. troglodytes) and humans. Future studies using a broader primate taxonomic sample and evidence derived from ontogenetic samples would certainly increase our understanding of the structural, functional and evolutionary aspects of primate facial musculature and its role in the evolution of human societies, cognition and speech/language. In addition the very close structural similarity between the facial muscles of rhesus macaques and those of humans reinforces the validity of using rhesus macaques as a model of human diseases and disorders that involve facial movement.

\section{Acknowledgements}

The present study was supported by a grant from the National Institute of Mental Health, NIH (grant no. 082282) and Yerkes Center Base Grant RR000165. The authors would like to thank Jeff Cohn, Katalin Gothard, Karen Schmidt and Chet Sherwood for useful discussion throughout the various phases of this work. In addition, we are very grateful to comments from the Receiving Editor, Dan Lieberman, and the two anonymous reviewers.

\section{References}

Abel K (2009) The rhesus macaque pediatric SIV infection model a valuable tool in understanding infant HIV-1 pathogenesis and for designing pediatric HIV-1 prevention strategies. Curr HIV Res 7, 2-11.

Amici F, Aureli F, Call J (2008) Fission-fusion dynamics, behavioral flexibility, and inhibitory control in primates. Curr Biol 18, 14151419.

Andrew RJ (1963) The origin and evolution of the calls and facial expressions of the primates. Behaviour 20, 1-109.

Aureli F, Schino G (2004) The role of emotions in social relationships. In Macaque Societies: A Model for the Study of Social Organization (eds Thierry B, Singh M, Kaumanns W), pp. 38-55. Cambridge: Cambridge University Press.

Bauman MD, Toscano JE, Babineau BA, Mason WA, Amaral DG (2008) Emergence of stereotypes in juvenile monkeys (Macaca mulatta) with neonatal amygdala or hippocampus lesions. Behav Neurosci 122, 1005-1015. 
Bearder SK, Honess PE, Ambrose L (1995) Species diversity among galagos, with special reference to mate recognition. In Creatures of the Dark: The Nocturnal Prosimians (eds Alterman L, Doyle GA, Izard MK), pp. 331-352. Pittsburgh: University of Pittsburgh Press.

Burrows AM (2008) Primate facial expression musculature: evolutionary morphology and ecological considerations. BioEssays 30, 212-225.

Burrows AM, Cohn JF (in press) Anatomy of the face. In Encyclopedia of Biometrics. New York: Elsevier.

Burrows AM, Smith TD (2003) Muscles of facial expression in Otolemur with a comparison to Lemuroidea. Anat Rec 274, 827836.

Burrows AM, Waller BM, Parr LA, Bonar CJ (2006) Muscles of facial expression in the chimpanzee (Pan troglodytes): Descriptive, ecological, and phylogenetic contexts. J Anat 208, 153-167.

Byrne RW, Bates LA (2007) Sociality, evolution and cognition. Curr Biol 17, R714-R723.

Chandrasekaran C, Ghazanfar AA (2009) Different neural frequency bands integrate faces and voices differently in the superior temporal sulcus. J Neurophysiol 101, 773-788.

Chapman CA, White FJ, Wrangham RW (1993) Defining subgroup size in fission-fusion societies. Folia Primatol 61, 31-34.

Cheney DL, Seyfarth RM (2007) Baboon Metaphysics: The Evolution of a Social Mind. Chicago: University of Chicago Press.

Clark US, Neargarder S, Cronin-Golomb A (2008) Specific impairments in the recognition of emotional facial expressions in Parkinson's disease. Neuropsychologia 46, 2300-2309.

Collier TJ, Lipton J, Daley BF, et al. (2007) Aging-related changes in the nigrostriatal dopamine system and the response to MPTP in nonhuman primates: diminished compensatory mechanisms as a prelude to parkinsonism. Neurobiol Dis 26, 56-65.

Combs DR, Tosheva A, Penn DL, Basso MR, Wanner JL, Laib K (2008) Attentional-shaping as a means to improve emotion perception deficits in schizophrenia. Schizophr Res 105, 68-77.

Darwin CR (1872) The Expression of Emotions in Man and Animals. London: J. Murray.

Das M, Penke Z, van Hooff JARAM (1998) Postconflict affiliation and stress-related behavior of long-tailed macaque aggressors. Int J Primatol 19, 53-71.

Degenhardt JD, de Candia P, Chabot A, et al. (2009) Copy number variation of CCL3-like genes affects rate of progression to simian-AIDS in Rhesus Macaques (Macaca mulatta). PLoS Genet 5(1) e 1000346.

de Waal FBM (1998) Chimpanzee Politics: Power and Sex among Apes. Baltimore: The Johns Hopkins University Press.

de Waal FBM, Aureli F (1996) Consolation, reconciliation, and a possible cognitive difference between macaque and chimpanzee. In Reaching into Thought: The Minds of the Great Apes (eds Russon AE, Bard KA, Parker ST), pp. 80-110. Cambridge: Cambridge University Press.

de Waal FBM, Luttrell L (1985) The formal hierarchy of rhesus monkeys; an investigation of the bared teeth display. Am $J$ Primatol 9, 73-85.

de Waal FBM, Yoshihara D (1983) Reconciliation and redirected affection in rhesus monkeys. Behaviour 85, 223-241.

Diogo R (2008) Comparative anatomy, homologies and evolution of the mandibular, hyoid and hypobranchial muscles of bony fish and tetrapods: a new insight. Anim Bio/ 58, 123-172.

Diogo R (2009) The head and neck muscles of the Philippine colugo (Dermoptera: Cynocephalus volans), with a comparison to tree-shrews, primates, and other mammals. J Morph 270, 14 51.
Dobson SD (2009) Allometry of facial mobility in anthropoid primates: implications for the evolution of facial expression. Am J Phys Anthropol 138, 70-81.

Dobson SD (in press) Socioecological correlates of facial mobility in nonhuman anthropoids. Am J Phys Anthropol.

Dunbar RIM (1998) The social brain hypothesis. Evol Anth 6, 178190.

Ekman, P (1999) Facial expressions. In The Handbook of Cognition and Emotion (eds Dalgleish T, Power M), pp. 301-320. Sussex, UK: Wiley.

Flack JC, de Waal FBM (2004) Dominance style, social power, and conflict management: a conceptual framework. In Macaque Societies: A Model for the Study of Social Organization (eds Thierry B, Singh M, Kaumanns W), pp. 157-181. Cambridge: Cambridge University Press.

Fleagle JG (1999) Primate Adaptation and Evolution. San Diego: Academic Press.

Fooden J (2000) Systematic review of the rhesus macaque, Macaca mulatta (Zimmermann, 1780). Field Zool 96, 1-180.

Foster MW, Gilby IC, Murray CM, Johnson A, Wroblewski EE, Pusey AE (2009) Alpha male chimpanzee grooming patterns: implications for dominance 'style'. Am J Primatol 71, 136144.

Fukuda F (1989) Habitual fission-fusion and social organization of the Hakone troop T of Japanese macaques in Kanagawa prefecture, Japan. Int J Primatol 10, 419-439.

Gerald MS, Waitt C, Little AC (2009) Pregnancy coloration in macaques may act as a warning signal to reduce antagonism by conspecifics. Behav Proc 80, 7-11.

Ghazanfar AA, Maier JX, Hoffman KL, Logothetis NK (2005) Multisensory integration of dynamic faces and voices in rhesus monkey auditory cortex. J Neurosci 25, 5004-5012.

Ghazanfar AA, Santos LR (2004) Primate brains in the wild: the sensory bases for social interactions. Nat Rev Neurosci 5, 603616.

Gil-da-Costa R, Braun A, Lopes M, et al. (2004) Toward an evolutionary perspective on conceptual representation: species-specific calls activate visual and affective processing systems in the macaque. Proc Natl Acad Sci USA 101, 17516-17521.

Goodall J (1986) The Chimpanzees of Gombe: Patterns of Behavior. Cambridge: Harvard University Press.

Gothard KM, Erickson CA, Amaral DG (2004) How do rhesus monkeys (Macaca mulatta) scan faces in a visual paired comparison task? Anim Cogn 7, 25-36.

Gothard KM, Battaglia FP, Erickson CA, Spitler KM, Amaral DG (2007) Neural responses to facial expression and face identity in the monkey amygdala. J Neurophysio/ 97, 1671-1683.

Gothard KM, Brooks KN, Peterson MA (2009) Multiple perceptual strategies used by macaque monkeys for face recognition. Anim Cogn 12, 155-167.

Groves C (2001) Primate Taxonomy. Washington, DC: Smithsonian Institution Press.

Hemelrijk CK, Wantia J, Isler K (2008) Female dominance over males in primates: self-organisation and sexual dimorphism. PLOS ONE 3, e2678.

Hinde RA, Rowell TE (1962) Communication by postures and facial expressions in the rhesus monkey (Macaca mulatta). Proc Zool Soc Lond 138, 1-21.

Hoffman KL, Gothard KM, Schmid MC, Logothetis NK (2007) Facial-expression and gaze-selective responses in the monkey amygdala. Curr Biol 17, 766-772.

Huber E (1931) Evolution of Facial Musculature and Expression. Baltimore: The Johns Hopkins University Press. 
Huber E (1933) The facial musculature and its innervation: In Anatomy of the Rhesus Monkey (eds Hartman CG, Straus WL, Jr), pp. 176-188. New York: Hafner Publishing Co.

Kempes M, de Vries H, Matthys W, van Engeland H, van Hooff J (2008) Differences in cortisol response affect the distinction of observed reactive and proactive aggression in children with aggressive behaviour disorders. J Neural Transm 115, 139-147.

Lightoller GS (1928) The facial muscles of three orang utans and two cercopithecidae. J Anat 63, 19-81.

Lightoller GS (1934) The facial musculature of some lesser primates and a Tupaia. Proc Zool Soc Lond 1934, 259-309.

Machado CJ, Bachevalier J (2008) Behavioral and hormonal reactivity to threat: effects of selective amygdala, hippocampal or orbital frontal lesions in monkeys. Psychoneuroendocrinology 33, 926-941.

Maestripieri D (1999) Primate social organization, gestural repertoire size, and communication dynamics: a comparative study of macaques. In The Origins of Language: What Nonhuman Primates Can Tell Us (ed. King BJ), pp. 55-77. Santa Fe: School of American Research Press.

Maestripieri D (2007) Macachiavellian Intelligence: How Rhesus Macaques and Humans Have Conquered the World. Chicago: University of Chicago Press.

Menard N, Hecham R, Vallet D, Chikki H, Gautier-Hion A (1990) Grouping patterns of a mountain population of Macaca sylvanus in Algeria - A fission-fusion system? Folia Primatol 55, 166-177.

Moss E (2008) Individual facial recognition in ring-tailed lemurs (Lemur catta). Prim Eye Special Issue 96, 229.

Murie J, Mivart St G (1872) On the anatomy of the Lemuroidea. Trans Zool Soc Lond 7, 1-113.

Nishida T (1979) The social structure of chimpanzees of the Mahale Mountains. In The Great Apes (eds Hamburg DA, McCown ER), pp. 73-121. Menlo Park, CA: Benjamin Cummings.

Parr LA (2003) The discrimination of faces and their emotional content by chimpanzees (Pan troglodytes). Ann NY Acad Sci 1000, 56-78.

Parr LA, Waller BM (2006) Understanding chimpanzee facial expression: insights into the evolution of communication. Soc Cogn Affect Neurosci 1, 221-228.

Parr LA, Hopkins WD, de Waal FBM (1998) The perception of facial expressions by chimpanzees, Pan troglodytes. Evol Comm 2, $1-23$.

Parr LA, Heintz M, Pradhan G (2008) Rhesus monkeys (Macaca mulatta) lack expertise in face processing. J Comp Psychol 122, 390-402.

Partan S, Marler P (1999) Communication goes multimodal. Science 283, 1272-1273.

Partan SR (2002) Single and multichannel signal composition: facial expressions and vocalizations of rhesus macaques (Macaca mulatta). Behaviour 139, 993-1027.

Partan SR, Marler P (2005) Issues in the classification of multimodal communication signals. Am Nat 166, 231-245.

Pellatt A (1979a) The facial muscles of Papio ursinus. S Afr J Sci 75, 30-37.

Pellatt A (1979b) The facial muscles of three African primates contrasted with those of Papio ursinus. S Afr J Sci 75, 436-440.

Pessa JE, Zadoo VP, Adrian EK, Jr, Yuan CH, Aydelotte J, Garza JR (1998) Variability of the midfacial muscles: analysis of 50 hemifacial cadaver dissections. Plast Reconstr Surg 102, 18881893

Preuschoft S (1992) 'Laughter' and 'Smiling' in barbary macaques (Macaca sylvanus). Ethology 91, 220-236.
Preuschoft S (2000) Primate faces and facial expressions. Soc Res 67, 244-271.

Preuschoft S (2004) Power and communication. In Macaque Societies: A Model for the Study of Social Organization (eds Thierry B, Singh M, Kaumanns W), pp. 56-60. Cambridge: Cambridge University Press.

Redican WK (1975) Facial expression in nonhuman primates. In Primate Behavior: Developments in Field and Laboratory Research (ed. Rosenblum LA), pp. 104-194. New York: Academic Press.

Rogers CR, Mooney MP, Smith TD, et al. (2009) Comparative microanatomy of the orbicularis oris muscle between chimpanzees and humans: Evolutionary divergence of lip function. J Anat 214, 3644.

Ruge G (1885) Uber die Gesichtsmuskulatur der Halbaffen. Morph Jahrb 11, 243-315.

Schmidt KL, Cohn JF (2001) Human facial expressions as adaptations: evolutionary questions in facial expression research. Yrbk Phys Anthropol 44, 3-24.

Schroeder CE, Lakatos P, Kajikawa Y, Partan S, Puce A (2008) Neuronal oscillations and visual amplification of speech. Trends Cogn Sci 12, 106-113.

Seth PK (2000) Habitat, resource utilization, patterns and determinants of behaviour in rhesus monkeys. J Hum Ecol 11, 1-21.

Sherwood CC (2005) Comparative anatomy of the facial motor nucleus in mammals, with an analysis of neuron numbers in primates. Anat Rec 287, 1067-1079.

Sherwood CC, Holloway RL, Gannon PJ, et al. (2003) Neuroanatomical basis of facial expression in monkeys, apes, and humans. Ann NY Acad Sci 1000, 99-103.

Sherwood CC, Holloway RL, Semendeferi K, Gannon PJ, Frahm HD, Zilles K (2005) Evolution of the brainstem orofacial motor system in primates: a comparative study of trigeminal, facial, and hypoglossal nuclei. J Hum Evol 48, 45-84.

Sherwood CC, Subiaul F, Zawidzki TW (2008) A natural history of the human mind: tracing evolutionary changes in brain and cognition. J Anat 212, 426-454.

Sonntag CF (1923) On the anatomy, physiology, and pathology of the chimpanzee. Proc Zool Soc Lond 23, 323-429.

Standring S (2004) Gray's Anatomy, 39th edn. London: Churchill Livingstone.

Swindler DR, Wood CD (1982) An Atlas of Primate Gross Anatomy. Malabar, FL: Robert E. Krieger.

Thierry B (1990) Feedback loop between kinship and dominance: the macaque model. J Theor Biol 145, 511-522.

Thierry B (2000) Covariation of conflict management patterns across macaque species. In Natural Conflict Resolution (eds Aureli F, de Waal FBM), pp. 106-128. Berkeley: University of California Press.

Tir M, Devos D, Blond S, et al. (2007) Exhaustive, one-year followup of subthalamic nucleus deep brain stimulation in a large, single-center cohort of parkinsonian patients. Neurosurgery 61, 297-304.

van Hooff JARAM (1962) Facial expressions in higher primates. Symp Zool Soc Lond 8, 97-125.

van Hooff JARAM (1972) A comparative approach to the phylogeny of laughter and smile. In Nonverbal Communication (ed. Hinde RA), pp. 209-241. Cambridge: Cambridge University Press.

van Hooff JARAM (1973) A structural analysis of the social behaviour in a semi-captive group of chimpanzees. In Expressive Movement and Nonverbal Communication (eds Von Cranach M, Vine I), pp. 75-161. London: Academic Press.

Waller BM, Vick SJ, Parr LA, et al. (2006) Intramuscular electrical 
stimulation of facial muscles in humans and chimpanzees: Duchenne revisited and extended. Emotion 6, 367-382.

Waller BM, Cray JJ, Jr, Burrows AM (2008a) Selection for universal facial emotion. Emotion 8, 435-439.

Waller BM, Parr LA, Gothard KM, Burrows AM, Vick SJ, Fuglevand AJ (2008b) Intramuscular electrical stimulation of facial muscles in the rhesus macaque. Phys Beh 95, 93-100.
Wu W, Brickman AM, Luchsinger J, et al. (2008) The brain in the age of old: the hippocampal formation is targeted differentially by diseases of late life. Ann Neurol 64, 698-706.

Zeller AC (1987) Communication by sight and smell. In Primate Societies (eds Smuts BB, Cheney DL, Seyfarth RM, Wrangham RW, Struhsaker TT), pp. 433-439. Chicago: University of Chicago Press. 